\title{
Influence of Calcium Alginate Coating on Quality of Pork Patties
}

\author{
E. Nagamallika, M. Sahitya Rani* and B. Eswara Rao \\ Sri Venkateshwara Veterinary University, Department of Livestock Products Technology, \\ NTR college of Veterinary Science, Gannavaram-521102, Andhra Pradesh, India \\ *Corresponding author
}

\section{A B S T R A C T}

\section{Keywords \\ Calcium alginate, Drip loss, Pork patties, Sodium alginate and Tannic acid \\ Article Info \\ Accepted: \\ 04 May 2018 \\ Available Online: \\ 10 June 2018}

The main objective of this study was to explain the use of calcium alginate coating in improving the quality attributes and in reducing the thawing loss of frozen pork patties. Five treatments were formulated- Control, $\mathrm{T}_{1}$ (coating with $1 \%$ alginate, cross linking with $3 \% \mathrm{CaCl}_{2}$ ), $\mathrm{T}_{2}$ (coating with $1 \%$ alginate, cross linking with $5 \% \mathrm{CaCl}_{2}$ ), $\mathrm{T}_{3}$ (coating with $3 \%$ alginate, cross linking with $3 \% \mathrm{CaCl}_{2}$ ) and $\mathrm{T}_{4}$ (coating with $3 \%$ alginate, cross linking with $5 \% \mathrm{CaCl}_{2}$ ). The results indicated that coating with calcium alginate can decrease thawing loss of patties. Addition of tannic acid into the coating can prevent lipid oxidation and microbial growth in calcium alginate coated patties. Drip loss was also decreased.

\section{Introduction}

Coating with edible materials in foods is considered as one of the methods to improve quality (Matuska et al., 2006). For meat processing industry, optimized procedures in favor of economics are of importance. Convenient frozen meat products are affected by the freezing process and time, which can greatly influence the thawing loss, cooking loss and tenderness. This can decrease the monetary value and quality of the product. The deleterious effects of freezing process can be alleviated by coating the products (Matuska et al., 2006). Alginate based coatings cross linked with calcium can form a good film over the product with increased water barrier properties. This can thus maintain the water and flavor of the product. Therefore this study was planned to explain the calcium alginate edible coating to improve the quality of frozen pork patties.

\section{Materials and Methods}

Deboned meat produced from the experimental abattoir of the Department of Livestock Products Technology, NTR College of veterinary sciences, Gannavarm was procured and pork patties were prepared with minced meat by addition of salt, fat, binder, spices and condiments at 1.8, 5.0, 3.0, 2.2 and $6.0 \%$, respectively. Emulsion was bowl chopped and patties were prepared with the batter.

Sodium alginate coating solution of different concentrations i.e. $1 \%$ and $3 \%$ were prepared 
by taking sodium alginate in distilled water and heating to $90^{\circ} \mathrm{C}$ on a magnetic stirrer until gelatinization was completed. Glycerin was added as plasticizer.

Pork patties were dipped in the coating solution for one minute. After dipping they were drained off the excess solution for 30 sec. The patties were then dipped in aqueous solution of calcium chloride $(3 \%, 2.5 \%)$ concentration for 30 seconds. The coated patties were kept in hot air oven for 10 minutes which allows the drying up of the coating and forms a film over the product. The quality of patties was evaluated for $\mathrm{pH}$, emulsion stability, water holding capacity, cooking loss. The better concentration of alginate with better cross linking concentration of calcium chloride was selected for further studies and subjected to frozen storage for two months. The coating solution for the patties to be frozen was added with tannic acid at $1 \%$ level. After two months of frozen storage, the patties were evaluated for $\mathrm{pH}$, emulsion stability, water holding capacity, cooking loss, thawing loss, thiobarbituric acid values and total plate counts. $\mathrm{pH}$ of the patties was calculated by using a standard $\mathrm{pH}$ meter (Deluxe pH meter model 101E). Emulsion stability of the patties was estimated by using the method of Baliga and Mandaiah (1970). Water holding capacity was measured by the method of Farouk et al., (2003) with some modification. Samples were weighed before $\left(\mathrm{W}_{\mathrm{b}}\right)$ and after $\left(\mathrm{W}_{\mathrm{a}}\right)$ they were held under pressure $(35 \mathrm{~kg})$ for $5 \mathrm{~min}$. The WHC of the pork patties was calculated according the following equation.

\section{$\mathrm{WHC}=\mathrm{Wa} / \mathrm{Wb} \times 100$}

Lipid oxidation was measured by 2- thio barbituric acid method of Cilla et al., (2006). Meat samples $(10 \mathrm{~g})$ were blended with $25 \mathrm{ml}$ of $10 \%$ Trichloroacetic acid and $2 \mathrm{ml}$ of the filterate was taken and mixed with $2 \mathrm{ml}$ of thio barbituric acid solution (20mM) and homogenized and incubated for $20 \mathrm{~min}$ in boiling water. Absorbance was measured at $532 \mathrm{~nm}$. Concentration of samples was calculated using a calibration curve. TBARS value was expressed as mg melanaldehyde/ $/ \mathrm{kg}$ prok. Total plate count was determined by following the method of Pearson (1973). The results were analyzed using SPSS (20.0) $(\mathrm{n}=6)$.

\section{Results and Discussion}

The results of application of different coating solutions with different levels of calcium chloride concentration on pork patties were presented in Table 1.

The results indicated that the concentration of calcium chloride in aqueous solution used for cross linking had no significant effect $(\mathrm{P}>0.05)$ on the physico chemical characteristics of pork patties. The concentration of sodium alginate had no significant effect $(\mathrm{P}>0.05)$ on $\mathrm{pH}$, emulsion stability and water holding capacity of the patties. The cooking loss was significantly $(\mathrm{P}<0.05) \quad$ decreased with increasing concentration of sodium alginate in coating solution. Even though the decrease was statistically significant, the amount of decrease was only meager.

Patties with $1 \%$ alginate coating and cross linked with $3 \%$ calcium chloride exhibited significantly $(\mathrm{P}<0.05)$ lower cooking loses and they were stored at frozen temperatures ($18 \pm 1^{0} \mathrm{C}$ ) for 2 months. The quality of calcium alginate patties after frozen storage was presented in Table 2. The results indicated that thawing loss was decreased significantly with calcium alginate coating. Percent cooking loss, thiobarbituric acid values and total plate counts were significantly $(\mathrm{P}<0.05)$ lower in coated patties when compared to control after 2 months of frozen storage. 
Table.1 Influence of calcium alginate coating on physic chemical properties of pork patties

\begin{tabular}{|c|c|c|c|c|c|}
\hline \multirow[t]{2}{*}{ Parameter } & \multirow[t]{2}{*}{ Control } & \multicolumn{2}{|c|}{ Coating with $1 \%$ Alginate } & \multicolumn{2}{|c|}{ Coating with 3\% Alginate } \\
\hline & & $\begin{array}{l}\left(\mathrm{T}_{1}\right) \text { Cross } \\
\text { linking with } \\
3 \% \mathrm{Cacl}_{2}\end{array}$ & $\begin{array}{l}\left(\mathrm{T}_{2}\right) \text { Cross } \\
\text { linking with } \\
5 \% \mathrm{Cacl}_{2}\end{array}$ & $\begin{array}{l}\left(\mathrm{T}_{3}\right) \text { Cross } \\
\text { linking with } \\
3 \% \mathrm{Cacl}_{2}\end{array}$ & $\begin{array}{l}\left(\mathrm{T}_{4}\right) \text { Cross } \\
\text { linking with } \\
5 \% \mathrm{Cacl}_{2}\end{array}$ \\
\hline $\mathrm{pH}$ & $5.54 \pm 0.14^{\mathrm{a}}$ & $5.55 \pm 0.06^{\mathrm{a}}$ & $5.61 \pm 0.19^{a}$ & $5.45 \pm 0.91^{\mathrm{a}}$ & $5.62 \pm 0.76^{\mathrm{a}}$ \\
\hline Cooking loss & $26.34 \pm 0.11^{\mathrm{a}}$ & $26.25 \pm 0.08^{\mathrm{a}}$ & $27.69 \pm 0.01^{b}$ & $25.98 \pm 0.04^{\mathrm{c}}$ & $25.85 \pm 0.17^{\mathrm{c}}$ \\
\hline WHC (\%) & $79.62 \pm 0.01^{\mathrm{a}}$ & $79.42 \pm 0.01^{\mathrm{a}}$ & $79.24 \pm 0.19^{a}$ & $79.17 \pm 0.07^{\mathrm{a}}$ & $79.42 \pm 0.24^{\mathrm{a}}$ \\
\hline Emulsion stability & $28.01 \pm 0.02^{\mathrm{a}}$ & $27.77 \pm 0.03^{\mathrm{a}}$ & $27.82 \pm 0.01^{\mathrm{a}}$ & $27.61 \pm 0.11^{\mathrm{a}}$ & $27.59 \pm 0.13^{\mathrm{a}}$ \\
\hline
\end{tabular}

Means bearing at least one common superscript do not differ significantly.

Table.2 The quality of calcium alginate patties after frozen storage.

\begin{tabular}{|l|l|l|}
\hline Parameter & Control & Treatment \\
\hline Thawing loss & $5.75 \pm 0.19^{\mathrm{a}}$ & $1.23 \pm 0.06^{\mathrm{b}}$ \\
\hline Cooking loss & $29.08 \pm 0.24^{\mathrm{a}}$ & $27.95 \pm 0.39^{\mathrm{b}}$ \\
\hline TBA values & $0.12 \pm 0.04^{\mathrm{a}}$ & $0.07 \pm 0.01^{\mathrm{b}}$ \\
\hline Total plate counts & $4.36 \pm 0.03^{\mathrm{a}}$ & $2.94 \pm 0.06^{\mathrm{b}}$ \\
\hline
\end{tabular}

Means bearing at least one common superscript do not differ significantly.

The lower cooking loss and thawing loss might be associated with lower evaporation and respiration due to coating. These results were in accordance with those of Geraldine et al., (2008) with agar-agar based coatings. The coatings did not affect the color of the product and they were transparent. The sensory quality of the product was not significantly affected by coating except for small improvement in juiciness of the product.

The results of fungi and mesophilic aerobic counts and TBARS showed the effectiveness of tannic acid present as antimicrobial and antioxidant agent in the active coatings. Rapid microbial growth took place in control and as well as in coating without addition of antimicrobial agent. The aqueous base of coating was not sufficient to maintain the quality of product in terms of microbial quality. Coatings without addition of tannic acid i.e. antimicrobial can lead to product deterioration. This might be due to aqueous base of coating which provides more water and favors microbial growth. The results were in accordance with that of Nagamallika et al., (2017) and Prathyusha et al., (2016). The thickness and water vapor transmission of co alginate coating were affected by the polysaccharide concentration.

\section{References}

Baliga, B. R., and Mandaiah, N. 1970. Quality of sausage emulsion prepared from mutton. Journal of Food Science. 35: 383-85.

Cilla, I., L. Martnez, J. A. Beltranand Roncales, P. 2006. Effect of low temperature preservatives on the quality of vaccum packaged dry cured ham: Refrigerated boneless ham and frozen ham cuts. Meat Sci. 73: 12-21.

Farouk, M. M., K. J, Wieliczko and Merts, I.2003. Ultrafast freezing and low storage temperatures are not necessary to maintain functional properties of manufacturing beef. Meat sci. 66: 171179. 
Matuska, M., A. Lenart and Lazarides, H. N. 2006. On the use of edible coatings to monitor osmotic dehydration kinetics for minimal solids uptake. J. Food. Eng. 72: 85-91.

Naga Mallika, E. D. Veena and Vijaya Bhaskar Reddy, G. 2017. Quality of Chicken Balls on Application of Edible Film Wraps Enriched with Natural Spice Oils. International Journal of Livestock Research. Vol 7(6): 202-210

Pearson, D., 1973. Flesh foods, meat and fish in laboratory techniques in food analysis $1^{\text {st }}$ edition. 166-212. Butter worths and Co (P) Ltd. London.
Prathyusha Kristam, Naga Mallika Eswarapragada, Eswara Rao Bandi and Srinivas Rao Tumati. 2016. Evaluation of edible polymer coatings enriched with green tea extract on quality of chicken nuggets. Vet World. 9(7): 685692.

Robson Maia Geraldine, Nilda de Fatima Ferreira Soared, Diego Alvarenga Botre Leticia de Almeida Goncalves. 2008. Characterization and effect of edible coatings on minimally processed garlic quality. Elsevier. Science direct. 72: 403-409.

\section{How to cite this article:}

Nagamallika, E., M. Sahitya Rani and Eswara Rao, B. 2018. Influence of Calcium Alginate Coating on Quality of Pork Patties. Int.J.Curr.Microbiol.App.Sci. 7(06): 824-827. doi: https://doi.org/10.20546/ijcmas.2018.706.097 